\title{
Condições microbiológicas e de ocorrência do caramujo terrestre africano na cidade de Araguaína no Estado do Tocantins.
}

\author{
Lilyan Rosmery LUIZAGA ${ }^{[1, *]}$, Fernanda Lima da SILVA ${ }^{[2]}$, Leurilene Barbosa SILVA ${ }^{[2]}$ \\ ${ }^{[1]}$ Universidade Federal do Tocantins (UFT), Campus Araguaína. Av. Paraguai esquina com Rua Uxiramas s/n, Cimba. 77824-838. Araguaína-TO, \\ Brasil. \\ ${ }^{[2]}$ Academicas do Curso de Licenciatura em Biologia da Universidade Federal do Tocantins (UFT), Campus Araguaína. Av. Paraguai esquina com \\ Rua Uxiramas s/n, Cimba. 77824-838. Araguaína-TO, Brasil. E-mail: lima45nanda@gmail.com; leurilenebarbosa@gmail.com
}

INFORMAÇÕES

Recebido em: 03/09/2015

Aceito em: $30 / 11 / 2015$

Publicado em: 23/12/2015

Document Object Identifier

$10.18067 /$ jbfs.v2i4.62

Termos de indexação:

Achatina fulica

Análise microbiológica

Canteiro

*Autor para correspondência

luizaga@uft.edu.br

\section{RESUMO}

Com base na grande incidência da espécie invasora de caramujo africano, Achatina fulica, na cidade de Araguaína, objetivamos investigar a relação existente entre as condições microbiológicas do caramujo e a ocorrência deste nas hortas domésticas na cidade. Foram seguidas metodologias laboratoriais na determinação de presença/ausência de microrganismos na superfície do caramujo, assim como de fungos filamentosos. Para complementar o trabalho foram entrevistados cento e um (101) moradores domiciliados em dezenove setores de Araguaína. Os resultados microbiológicos da superfície do caramujo apresentam valores acima de 1,2×10 $\mathrm{UFC} / \mathrm{g}$ de bactérias heterotróficas, foram também isolados fungos dos gêneros Aspergillus, Penicillum, Trichophyton e Cryptococcus. No levantamento por entrevista, $86 \%$ dos entrevistados relataram uma alta incidência do caramujo nos seus domicílios no período chuvoso e $50 \%$ deles afirmaram ter algum tipo de canteiro em casa, porém $85 \%$ desconhecem as doenças que poderiam ser transmitidas por este caramujo. Concluímos que existe uma elevada contaminação microbiológica na superfície dos caramujos analisados, o que combinado com a preferência pelos produtos de hortas domesticas desconhecendo os riscos que a invasão por caramujos pode acarretar, indicam a necessidade de ampliar o conhecimento sobre a determinação das condições de risco inerentes a A. fulica, assim como sua divulgação na sociedade araguaínense sobre seus efeitos, não somente na saúde das pessoas mas também na produtividade da agricultura artesanal.

\section{Microbiological conditions and occurrence of the African land snail in Araguaína city at Tocantins State, Brazil}

ABSTRACT- Based on the high incidence of invasive species of the African snail, Achatina fulica, in Araguaína city, we aimed to investigate the relationship between the microbiological conditions of the snail and the occurrence of this in home gardens in the city. Laboratory methods were followed to determine the presence / absence of microorganisms at the snail's surface, as well as filamentous fungi. In addition there were performed hundred and one (101) interviews to locals settled in nineteen sectors of Araguaína. The microbiological results from the snail surface analysis showed at least 1,2x105 CFU/g of heterotrophic bacteria, also were isolated fungi as Aspergillus, Penicillium, Trichophytone and Cryptococcus. In the survey interview, $86 \%$ of respondents reported a high incidence of snail in their homes during the rainy season and $50 \%$ of them informed they had some kind of home garden, on the other hand $85 \%$ are unawared of the diseases that could be transmitted by this snail. We conclude that there are high levels of microbial contamination on the snail surface, combined with the preference for domestic garden's products, been unawared of risks that can be carried by the snail invasion, which indicate the need to improve the knowledge regarding the risks of $A$. fulica in the daily lives of the residents of Araguaína city, considering not only people's health but also the productivity of small-scale agriculture.

Index terms: Achatina fulica, análise microbiológica, canteiro

c) (i) (2) Copyright: () 2015 JBFS all rights. This is an open-access article distributed under the terms of the Creative (c) ${ }_{\mathrm{EY} \text { NC SA }}$ Commons Attribution License, which permits unrestricted use, distribution, and reproduction in any medium, provided the original author and source are credited.

Financiamento: Os autores reportam que houve auxílio ou financiamento pelo Conselho Nacional de Desenvolvimento Científico e Tecnológico (CNPQ) com bolsa de iniciação científica.

Conflito de interesse: Os autores declaram que não há conflito de interesse.

Como referir esse documento (ABNT):

MONTEIRO, L. R. L.; SILVA, F. L.; SILVA L. B. Condições microbiológicas e de ocorrência do caramujo terrestre africano na cidade de Araguaína no Estado do Tocantins. Journal of Bioenergy and Food Science, Macapá, v.2, n.4, p.234-238, out./dez., 2015. http://dx.doi.org/10.18067/jbfs.v2i4.82 


\section{INTRODUÇÃO}

O caramujo africano Achatina fulica Bowdich, 1822, atualmente ocupa o segundo lugar no banco de dados global sobre espécies mais invasoras [1]. Foi introduzido no Brasil para o cultivo e comercio como alimento humano conhecido como"escargots" em 1988 [2], teve pelo menos mais duas ocasiões de reintrodução importantes com interesse na alimentação, como fonte nutritiva, devido a seu conteúdo proteico de $88,37 \%$, um pouco menor que o existente na carne de gado $(92,75 \%)$ mas algo maior que o da carne de porco $(82,42 \%)$, a esta qualidade se junta o atrativo de possuir baixas concentrações de gordura e de ser fonte de ferro [3].

Atualmente esta espécie já está distribuída em 24 estados e o Distrito federal e vem causando incômodos, danos e risco de zoonoses, Zanol [4], além de efeitos negativos sobre a agricultura, como detalhado por Freire [5] que indica que o ataque pode alcançar mais de 300 espécies de plantas no mundo inteiro, ao que outros autores como Mathew [6] já indica que são 500 espécies de plantas, incluindo pomares, canteiros e incluso plantas de café.

Segundo Teles [2] existem registros da introdução da espécie ao continente americano já em 1939, também coloca a sua característica de praga agrícola nos EUA e Austrália onde foram implementadas estratégias de controle e erradicação. Atualmente autores como Fukahori e Zequi [7] consideram que mudanças nos fatores ambientais, econômicos e sociais estariam facilitando a proliferação de espécies invasoras nos ecossistemas agrícolas, urbanos e naturais.

Então, além dos protozoários de interesse na saúde humana, os caramujos também têm sido associados com a transmissão de bactérias patogênicas, como Listeriamonocyto genes, e outras bactérias altamente patogênicas, como detectado por Adegoke [3], além de outras bactérias gram negativas como Aeromonashydrophila que comprometem principalmente o sistema imunológico [8], em nosso entorno, se desconsidera o potencial de risco pelo consumo, mas se enfatiza o caráter de sua distribuição descontrolada ao se tornar verdadeiras pragas urbanas e desta forma conviver próximo ao homem.

O caramujo africano pode ser hospedeiro intermediário do nematoide Angiostrongylus cantonensis, descrito inicialmente por Chen em 1935, causador da angiostrongilia meningoencefálica além de lesões oculares permanentes, sendo roedores urbanos e silvestres os hospedeiros definitivos da verminose [2]. Vasconcellos e Pile [9] (2001) indicam que mesmo não detectando caramujos infetados por $A$. cantonensis a ocorrência dos mesmos deve originar a preocupação das autoridades de saúde pública, pois segundo Teles et al. [2]; Silva e Aleluia [10] A. fulica além de apresentar uma produção maior de larvas do que outros moluscos, entre 100 a 600 ovos por acasalamento, também e mais susceptível ao parasita.

Por isso, o presente trabalho tem como objetivo principal realizar um levantamento das condições microbiológicas e de presença do caramujo africano Achatina fulica na cidade de Araguaína, Tocantins.

\section{MATERIAL E MÉTODOS}

\section{a) Trabalho de campo e procedimentos de coleta}

Depois de reconhecido o caramujo africano (Figura 1A), a pesquisa foi realizada entre os meses de abril e agosto de 2015 no município de Araguaína, localizado ao norte do Estado do Tocantins, entre $07^{\circ} 11^{\prime} 28^{\prime \prime} \mathrm{S}$ e $48^{\circ} 12^{\prime} 26^{\prime}$ 'W, o clima é úmido e quente com estação seca entre junho e agosto [11]. Foram realizadas visitas exploratórias para determinar os pontos de maior incidência do caramujo, determinando a posição com relação à densidade de pessoas, fontes hídricas e outros fatores ambientais.

\section{b) Procedimentos laboratoriais}

Os Procedimentos microbiológicos foram realizados no Laboratório de Biologia do Curso de Biologia da UFT- Araguaína.

Foi pesquisada a presença/ausência de microrganismos da superfície do caramujo assim como da massa corpórea, por contagem padrão de microrganismos mesófilos aeróbios estritos e facultativos viáveis assim como a de fungos filamentosos cujos procedimentos microbiológicos seguiram as recomendações da Instrução Normativa $\mathrm{N}^{\circ} 62$ [12] e a preparação da amostra segundo utilizada por Adegoke et al. [3].

\section{c) Trabalho de campo e aplicação de formulários}

Para complementar a pesquisa, foi investigado o conhecimento da população sobre $A$. fulica e sobre a sua postura referente ao combate a este caramujo.

Foram levantados dados qualitativos no registro de bairros/setores de ocorrência do 
caramujo na cidade de Araguaína, e sua relação com o conhecimento da comunidade a respeito do caramujo, como realizado por Fisher e Colley [13] usando como instrumento a aplicação de questionários e entrevistas estruturadas e semiestruturadas.

$\mathrm{Na}$ pesquisa quantitativa, foi aplicado questionário a moradores de diferentes bairros/setores de Araguaína, para saber o grau de conhecimento sobre o potencial de risco que o caramujo na transmissão protozoários e microrganismos de importância na área da saúde, ao mesmo tempo para mostrar a frequência de famílias que utilizam a agricultura artesanal (Figura 1B).

Figura 1. Canteiros em Araguaína - TO. Achatina fulica em domicilio do setor Araguaína Sul (A). Horta artesanal em bairro do setor Cimba (B).
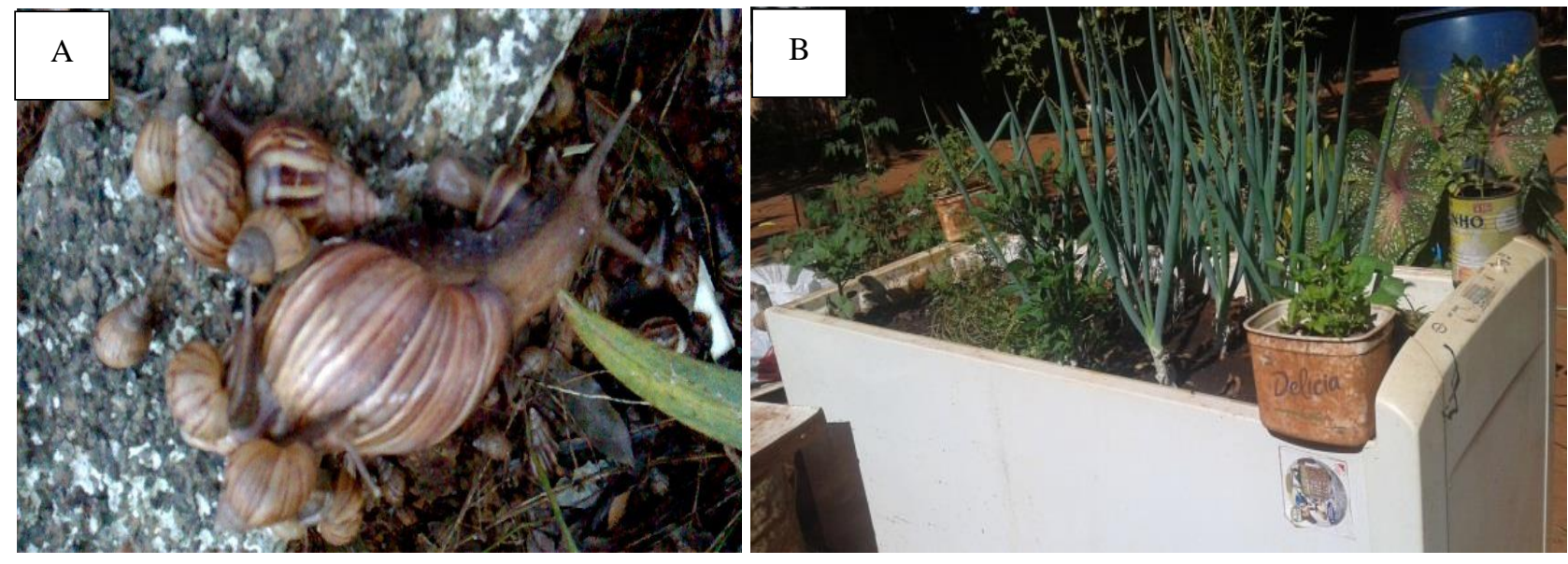

\section{RESULTADOS E DISCUSSÃO}

$\mathrm{Na}$ superfície do caramujo foram identificadas bactérias aeróbias mesófilas com valores acima de $1,2 \times 10^{5} \mathrm{UFC} / \mathrm{g}$, foram também isolados fungos dos gêneros Aspergillus, Penicillum, Trichophytone leveduras do gênero Cryptococcus. Segundo Adegoke, et al [13] estes caramujos tem uma importância epidemiológica também por veicular bactérias patogênicas, como as identificadas pelos autores, onde foram associados fungos e bactérias a casos clínicos, como aspergilose e toxinfecções.

No que se refere à forma de controle entre os moradores entrevistados, $45 \%$ indicam que utilizam sal e $31 \%$ que descartam no lixo. Coelho [14] e César [15] sugerem que devem ser descartados em valas impermeabilizadas de aproximadamente $40 \mathrm{~cm}$ de profundidade por uma camada de cal virgem, pois mesmo quando os caramujos morrem, a sua concha pode servir de foco de mosquitos como o Aedes aegypti, como mencionado por Coelho [14].

Quando consideramos os hábitos entre os moradores tocantinenses como o consumo de sucos de frutas produzidos artesanalmente e de verduras e legumes de hortas familiares (Figura 1), junto à elevada incidência de caramujos na estação chuvosa, observa-se o risco inerente destes alimentos expostos e susceptíveis ao contato com estes caramujos.

Segundo pesquisas realizadas por Brito e Rossi [16], a contaminação microbiana nos sucos in natura pode ter como uma das fontes a parte externa das frutas, por isso surge à necessidade de ampliar o conhecimento sobre a determinação das condições microbiológicas relacionadas à espécie A. fulica, o que pode dar um indicativo sobre o atual cenário de risco à saúde da população da região.

A partir deste trabalho pretende-se iniciar uma campanha informativa sobre prevenção na manipulação dos caramujos, mecanismos de controle e riscos à saúde relacionados com A. fulica. Visto que atualmente este caramujo é considerado uma praga devido a sua alta capacidade de reprodução, adaptação a diferentes ambientes e ausência de predadores, sendo necessário também o monitoramento da população dos mesmos para reavaliar as medidas de controle de acordo com as características regionais e a ação das autoridades em saúde coletiva.

\section{CONCLUSÃO}

Os valores elevados na contagem de bactérias heterotróficas e presença de vários tipos de fungos, revelam o perigo deste molusco na transmissão de patógenos bacterianos, pois ao transitar por vários 
lugares acabam levando consigo contaminação e por sua vez contaminando as hortas pelas quais eles passam.

Os moradores de Araguaína mostram-se desinformados, pois de uma centena de entrevistados $85 \%$ indicam desconhecer algum tipo de doença que pode ser transmitida por estes moluscos.

Oitenta e seis pessoas entrevistadas relataram uma elevada incidência de caramujo nos seus domicílios, pode-se afirmar que o sistema deficiente de drenagem pluvial da cidade favorece a distribuição dos caramujos para locais mais afastados ao se formar verdadeiros rios nas ruas.

A falta de limpeza e roçagem de lotes vazios favorecem a permanência e multiplicação do caramujo africano, o que indica a necessidade de realizar pesquisas exploratórias e trabalhos de extensão na prevenção de doenças que podem ser transmitidas por estes caramujos e controle dos mesmos, que envolva tanto as autoridades de saúde como a população no combate seguro ao caramujo africano.

\section{CONTRIBUIÇÃO DOS AUTORES}

1. Condução e avaliação do experimento, aplicação de questionário e elaboração do artigo:

Fernanda Lima da Silva

Leurilene Barbosa Silva

2. Planejamento, orientação e revisão final do artigo

Dr $^{\mathrm{a}}$. Lilyan Rosmery Luizaga de Monteiro

\section{REFERÊNCIAS}

[1]. SOBREPEÑA, J.M.M.; DEMAYO C.G. Banding pattern and shape morphology variations on shells of the invasive giant African land snail Achatinafulica (Bowdich 1822) from the Philippines. Annals of Biological Researh. v.5, n.1, 2014.

[2]. TELES, H. M. S.; VAZ, J. F.; FONTES, L. R.; DOMINGOS, M. F. Registro de AchatinafulicaBowdich 1822 (Mollusca, Gastropoda) no Brasil: caramujo hospedeiro intermediário da angiostrongiliáse. Revista de Saúde Pública. v.31, n.3, 1997. http://dx.doi.org/10.1590/S0034$\underline{89101997000300014}$

[3]. ADEGOKE, A. A.; ADEBAJO-TAY; BUKOLA, C.; COMFORT, I. U.; OLAYINKA, A.; AMOS, K. O. Snails as meat source: Epidemiological and nutritional perspectives. Journal of Microbiology and Antimicrobials. v.2, n.1, p.1-5, 2010.

[4]. ZANOL, J.; FERNANDEZ MA; OLIVEIRA, A.P.M.; THIENGO, S.C. The exotic invasive snail Achatina fulica (Stylommatophora, Mollusca) in theStateof Rio de Janeiro (Brazil): current status.

Biota Neotrop v.10. n.3, 2010. p. 447-451. http://dx.doi.org/10.1590/S167606032010000300038

[5]. FREIRE, F. das C.O. Ocorrência do CaramujoAfricano (Achatina fulica) Atacando Cactáceas no Estado do Ceará. Fortaleza: Embrapa agroindústria tropical, 2011. 4 p. (Embrapa agroindústria tropical. Comunicado Técnico, 173).

[6]. MATHEW, R. Thiruvananthapuram, profiles of Nature. The Hindu. [on line] 2010. Disponível em: <http://natureprofiles.hpage.co.in/snails 76484379 . html>. Acesso em: 10. Abr. 2015.

[7]. FUKAHORI, M. S. F. ;ZEQUI, J. A. C. Vigilância Ambiental em Saúde: considerações sobre o molusco Acahatinafulica (Bowdich, 1822) e sua ocorrência na cidade de Londrina - PR. In: Qualidade de vida em Londrina: um enfoque ambiental / organizadores João Antonio Cyrino Zequi, Miriam Ribeiro Alves Maiola. - Londrina: Unifil, 2014. p. 165-182.

[8]. SANKARAN, KV. 2012. Pest Fact Sheet: Giant African Snail. Asia-Pacific Forest Invasive Species.Newsletter of the Asia-Pacific Forest Invasive Species Network/Food and Agriculture Organization of the United Nations (APFISN/FAO). Network. Disponível em: <http://www.fao.org/forestry/220710a714b2449327eb9db0f552d36311fdd7.pdf >.

Acesso em: 8. Abr. 2015

[9]. VASCONCELLOS, M.C.; PILE, E. Ocorrência de Achatinafulica no Vale do Paraíba, Rio de Janeiro, Brasil. Revista de Saúde Pública. v. 35, n. 6, 2001. http://dx.doi.org/10.1590/S0034$\underline{89102001000600013}$

[10]. SILVA, E.C.; ALELUIA, F.T.F. Ocorrência de Achatinafulica Bowdich, 1822 (Mollusca, Gastropoda). Nota científica. Revista Brasileira de Zoociências. v. 12. n.2, p. 199-204. 2010.

[11]. MACHADO, C.A.; OLIVEIRA, V.M. Planejamento ambiental para a Cidade de Araguaína - TO. Interface. Porto Nacional/TO. v.2, n.2, p. 52-65. 2005.

[12]. BRASIL, Ministerio de Agricultura do Abastecimento e da Reforma Agrária. Secretaría de Defesa Agropecuária. Instrução Normativa No 62, de 26 de agosto de 2003. Oficializa os Métodos Analíticos Oficiais para Análises Microbiológicas para Controle de Produtos de Origem Animal e Água. Diário Oficial da União, Brasília, DF. p.14, de 18 de setembro de 2003. Seção 1.

[13]. FISHER, M.L.; COLLEY, E. Diagnóstico da ocorrência do caramujo gigante africano AchatinafulicaBowdich, 1822 na APA de 
Guaraqueçaba, Paraná, Brasil. Revista Estudos de Biologia. v.26, n. 54, p. 43-50, 2004.

[14]. COELHO, L. M. Informe técnico para o controle do caramujo africano (Achatina fulica, (Bowdch 1822) em Goiás, Goiânia: Agencia Rural, 2005.12 p. AGENCIA RURAL. Documento 4.

[15]. CÉSAR, J. Saúde divulga medidas de controle do caramujo africano. 2014. Comunicação [online] da Prefeitura de Blumenau. Disponível em: <http://www.blumenau.sc.gov.br/secretarias/secreta ria-de-saude/semus/saude-divulga-medidas-decontrole-do-caramujo-africano-14>. Acesso em: 31. Mar. 2015.

[16]. BRITO, C. S.; ROSSI, A. Bolores e leveduras, coliformes totais e fecais e sucos de laranja in natura e industrializados não pasteurizados comercializados na cidade de Uberlância - MG. Bioscience Journal. v.21, n.1, p.133-140, 2005. 